\title{
Article \\ Research on the Impact of Factor Flow on Urban Land Use Efficiency from the Perspective of Urbanization
}

\author{
Xinhai Lu ${ }^{1,2}$, Zhenxing Shi ${ }^{2}$, Jia Li ${ }^{2, *}$, Junhao Dong ${ }^{2}$, Mingjie Song ${ }^{2}$ and Jiao Hou ${ }^{2}$ \\ 1 College of Public Administration, Huazhong University of Science and Technology, Wuhan 430074, China; \\ luxinhai@hust.edu.cn \\ 2 College of Public Administration, Central China Normal University, Wuhan 430079, China; \\ s41528@mails.ccnu.edu.cn (Z.S.); fldjh@mails.ccnu.edu.cn (J.D.); smingjie@ccnu.edu.cn (M.S.); \\ houjiao@mails.ccnu.edu.cn (J.H.) \\ * Correspondence: lijia-wh@mails.ccnu.edu.cn
}

Citation: Lu, X.; Shi, Z.; Li, J.; Dong, J.; Song, M.; Hou, J. Research on the Impact of Factor Flow on Urban Land Use Efficiency from the Perspective of Urbanization. Land 2022, 11, 389. https://doi.org/10.3390/ land11030389

Academic Editor: Fabrizio Battisti

Received: 5 February 2022

Accepted: 5 March 2022

Published: 6 March 2022

Publisher's Note: MDPI stays neutral with regard to jurisdictional claims in published maps and institutional affiliations.

Copyright: (C) 2022 by the authors. Licensee MDPI, Basel, Switzerland. This article is an open access article distributed under the terms and conditions of the Creative Commons Attribution (CC BY) license (https:// creativecommons.org/licenses/by/ $4.0 /)$.

\begin{abstract}
Researching the impact of factor flow on urban land use efficiency (ULUE) is significant in alleviating the contradiction between the accelerated promotion of urbanization and the inefficient use of urban land. This paper theoretically analyzes the impact mechanism of the flow of the three major factors of production-land, capital, and labor-on ULUE. On this basis, taking 54 cities in the urban agglomeration in the middle and lower reaches of the Yangtze River in China as the research object, the stochastic frontier model, fixed effect model, and K-means clustering method are used to empirically analyze the impact of the flow of labor, capital, and land on ULUE. The heterogeneous effect of factor flow on ULUE in different urbanization stages is also discussed. The results are as follows: (1) Labor flow and capital flow play a significant role in promoting ULUE; land flow plays the opposite role. (2) With the continuous improvement of the level of urbanization, the promotion effect of labor flow first decreases and then increases, while the promotion effect of capital flow continues to decrease, and the inhibitory effect of land flow is significant in the initial stage and expansion stage of urbanization, and the effect increases gradually, but it is not significant in the mature stage. (3) The level of urbanization has an obvious threshold effect on factor flow. There are single thresholds for labor and land flow, and there is a double threshold for capital flow. Research conclusions: we should continue to promote the market-oriented reform of factors, break the institutional shackles which restrict the free flow of factors, implement policies according to the city and the stage, and give full play to the positive impact of factor flow on ULUE.
\end{abstract}

Keywords: urban land use efficiency; factor flow; urbanization; urban agglomeration in the middle and lower reaches of the Yangtze River

\section{Introduction}

Cities are the main regional development body, and urban land is the material carrier of regional development. Therefore, its utilization status has an important impact on social and economic development, the quality of urban development, and the construction environment of human settlements. Moreover, it plays a vital role in promoting coordinated regional development [1,2]. Urban land use efficiency (ULUE) is the ratio of input to the output of economic, social, and ecological factors brought about by the interaction of capital and labor carried by urban land use areas. It is an essential basis for measuring the comprehensive level of urban land use and a key indicator for researching the comprehensive benefits of urban land use [3].

At present, urbanization in the world is advancing rapidly, especially in developing countries. However, in the process of urbanization, problems such as waste of urban land, improper utilization, and low efficiency have seriously inhibited the improvement of ULUE and further hindered the sustainable development of cities [4]. Existing research shows that urbanization affects ULUE mainly by affecting the communication path and intensity 
of factors such as land, capital, and labor [5,6]. As the largest developing country in the world, China's urbanization rate has increased by nearly 14 percentage points in the past decade, reaching $64.72 \%$ by 2021 . Stiglitz, the Nobel laureate, calls China's urbanization one of the two major events affecting human progress in the 21st century [7]. However, in rapid urbanization in China, there are also problems such as rapid growth of urban construction land, the scattered land layout within cities, and extensive use of inefficient land in cities. So, what role do the factors of production such as land, capital, and labor play in it? It is of great significance to research this problem to alleviate the contradiction between accelerated urbanization and inefficient use of urban land.

Scholars have carried out much research on ULUE, and the existing research mainly focuses on the evaluation of ULUE and ULUE-impacting mechanisms. In the evaluation of ULUE, the measurement methods mainly include the non-parametric methods represented by data envelopment analysis (DEA) [8,9] and parameter methods represented by stochastic frontier analysis (SFA) $[10,11]$. The essence of DEA is to determine the relative effective points of each evaluation unit on the frontier of production based on the principle of Pareto optimality to measure the relative efficiency of ULUE. The disadvantage is that the evaluation unit cannot be analyzed from time series. SFA is based on the production function, adding the error term to the production function to measure the absolute efficiency of ULUE, which can make up for the disadvantage that the DEA cannot be analyzed from a time sequence [12]. Scholars have used the above methods to evaluate the ULUE of provincial [9] and municipal [13] scale units, summarize the characteristics of temporal and spatial evolution according to the specific land use situation of the research area, and put forward policy suggestions for land use. With the advancement of urbanization, the evaluation of ULUE of urban agglomerations has become a research hot spot $[4,14]$. The land use activities of urban agglomerations are frequent and complex, so the evaluation of ULUE is more complex than that of a single city. From the aspect of the impact mechanism of ULUE, researchers have made abundant achievements. First of all, the comprehensive attributes of the city itself, especially the economic attributes, have a significant effect on ULUE [15]. Land is one of the most important factors in urban economic activities. The stronger the urban economic foundation is, the more reasonable the economic structure is, and the higher the ULUE is [16]. In addition to economic attributes, researchers also have comprehensively investigated the impacting factors of ULUE from the aspects of nature, society, environment, culture, science, and technology and built a comprehensive system of indicators affecting ULUE [17-19]. In addition, local government behavior impacts ULUE, which mainly affects ULUE by adjusting land structure and land fiscal behavior [20]. The change of urban land use structure leads to the change of urban spatial structure, which affects the input scale of various types of land through traffic accessibility and spatial plane distance, thus affecting ULUE. Land fiscal behavior will stimulate the government to develop construction land and expropriate agricultural land. Moderate and scientific land transfer behavior can promote local economic development. However, the shortsighted large-scale land transfer behavior of local governments will cause imbalances in the structure of the land market, which will reduce ULUE [21].

Existing research has evaluated ULUE in different regions, summarized its temporal and spatial characteristics, and analyzed the impact mechanism of ULUE from the aspects of economic development level, scientific and technological innovation, government behavior, etc., which are of great significance to enrich the theoretical system of land use efficiency and to improve ULUE. However, according to the theory of neoclassical economics, the development of a region's economy is closely related to factors of production such as labor, capital, and land. Economic development is largely restricted by factors of production, which cannot achieve the optimal state. The famous Lewis dual economic structure model holds that the flow of factors of production from rural areas to urban areas promotes the transformation of dual economic structure and economic development [22]. In rapid urbanization in China, many factors of production such as labor, land, and capital flow from rural areas to urban areas. The flow of factors of production among regions is conducive to 
absorbing surplus labor, realizing the upgrading and optimization of regional industrial structure, and promoting economic growth. In addition, the flow of factors of production can improve production relations among regions, promote the equalization of factor income, and narrow the gap between urban and rural areas [23]. As the carrier of various economic activities, the flow of factors will undoubtedly change the level of factors input in urban land use activities and affect ULUE. However, at present, few scholars have researched the relationship between factor flow and ULUE. They have measured the effectiveness of the flow of different factors of production on ULUE. At the same time, affected by factors such as resource endowment, geographical location, national strategy, economic and social conditions, the urbanization stage of each city is different. As a result, there are significant differences in the level of factor flow in different urbanization stages. Therefore, when discussing the relationship between factor flow and ULUE, the urbanization stage of the city should be taken into account.

In view of this, this research explores the impact of factor flow on ULUE against the background of urbanization. Taking 54 cities in the middle and lower reaches of the Yangtze River in China as the research object, panel data from 2009 to 2018 are used to empirically analyze the impact of the flow of labor, capital, and land and to explore the heterogeneity of factor flow on ULUE in different stages of urbanization. This will enrich the content of ULUE research, provide targeted policy support for improving China's ULUE, and provide an empirical reference for other developing countries that are rapidly promoting urbanization to improve their ULUE through the rational and efficient use of various factor resources.

\section{Theoretical Framework and Hypotheses}

According to Lynch's urban-rural dynamics theory, urbanization is the dominant process of urban and rural factor flow. The flow of factors of production from rural to urban areas is the endogenous path of urbanization [24]. Since the reform and opening up, the development of urbanization in China has accompanied the changes of factor flow and ULUE. ULUE and factor flow are connoted in the development process of urbanization and resonate with the development of urbanization at the same frequency.

In the early stage of urbanization, the level of urban specialization is generally not high. The gap in technology level is small, and there is even a certain degree of homogeneous competition [25]. Due to household registration policies and transportation conditions, it is difficult for the labor force to achieve large-scale, long-distance, and long-term flow [26]. In terms of land factors, affected by the planned economy system, the government monopolizes the supply of urban land resources, the market-oriented allocation level of land factors is not high, the market economy is difficult to establish, and the capital market is difficult to form [27]. At that time, the factors of production are relatively fixed, and various materials, population, information, science and technology, and capital factors flow slowly in urban land space. With the accumulation of capital, institutional innovation, and market opening in economic system reform, the market economy has continued to develop, the speed of regional factor flow has accelerated, and the degree of factor marketization has continuously improved. A large amount of agricultural land is expropriated as urban construction land, and the population and capital quickly gathered in the cities. The urban areas with the advantages of agglomeration economy attract a large number of rural labor, capital, land, and other factors [28]. The economic volume, population scale, and land area expand significantly, accelerating the improvement of urbanization.

So, how does factor flow affect ULUE in this process? On the one hand, the factor flow will affect ULUE through factor agglomeration and a multiplier effect to improve economic efficiency, which is called the 'direct effect' in this paper. On the other hand, factor flow will affect ULUE through spillover effects and changes in the supply and demand relationship, which is called the 'indirect effect' in this paper. 


\subsection{Direct Effect}

The direct effect of factor flow on ULUE comes from an agglomeration economy. According to neoclassical economic theory, since the regional prices of factors of production cannot be consistent, there are differences between the price of labor and the rate of return on capital between regions [29]. Therefore, this kind of economic factor, ultimately formed by transportation costs and local interests, is essential for the flow between factors.

In China, due to the restricted dual economic structure of urban and rural areas, the average wage of laborers in urban areas is significantly higher than that in rural areas, and the supply of urban labor factors exceeds the demand. According to the theory of supply and demand, urban areas will become a net labor inflow area, and rural areas will become a net labor outflow area. The inflow of labor factors from the agricultural sector, with low marginal productivity, to the non-agricultural sector can reduce the marginal labor productivity gap between sectors [30] and does not change the effective supply of rural labor due to the relative surplus of rural labor. Therefore, the net economic benefits obtained by labor flow in the early stage of urbanization should be positive, and it should also play a role in promoting ULUE. Similarly, from the perspective of investment cost and return on investment, the return on investment in urban areas is better than that in rural areas. In population urbanization, farmers' assets are gradually transformed into citizens' assets. Due to the scale effect of capital, within a certain range, the increase in asset scale will significantly promote the improvement of urban production efficiency, which will also promote the improvement of ULUE. In addition, the inflow of labor and capital into cities will bring about the integration and expansion of the inflowing regional markets, and the difference in factor endowments will promote specialization and division [31], which will broaden and deepen the market size and drive consumption growth. The 'growth pole' will also promote the development of industry and services, promote the agglomeration of urban land factors, promote the optimal allocation of land resources, greatly promote the process of urbanization, and ultimately promote the improvement of ULUE [32].

\subsection{Indirect Effect}

The indirect effect of factor flow on ULUE comes from the spillover effect. From the perspective of factor spillover, on the one hand, in the transfer of factors from the peripheral area to the central area, the agglomeration effect of the central area is enhanced [33]. In the process of economic growth in the central region, capital, labor, and land factors form agglomeration economies and economies of scale through shared infrastructure, industrial matching, and learning effects, promoting the upgrading and transformation of industrial structure, and driving the development of dominant industries [34], and then promoting the improvement of ULUE. At the same time, the positive externalities that generate technological spillovers drive the factors to flow bidirectionally between regions, forming the spillover effect of ULUE [35]. On the other hand, in the middle and late stages of urbanization development, the degree of regional integration is deepened, the networked gathering of factors will attract greater high-value-added industrial space agglomeration, and the industrial structure will be adjusted to the advanced level, which will promote the structural adjustment of land use, and finally promote the coordination of land use and industrial development [36,37]. In the later stage of urbanization, the industrial transfer will occur due to the carrying capacity of resources. This kind of cross-regional transfer of industrial and production factors can further improve the intensity and efficiency of land in surrounding areas [4].

From the perspective of balanced supply and demand of factors, the flow of factors of production from low-yield rural areas to high-yield urban areas gradually realizes the stability of factor supply. The improvement of the supply and demand environment promotes the equalization of labor and capital prices, which is conducive to narrowing the gap in commodity production costs between regions and indirectly improving ULUE. In addition, because the provision of various infrastructure will only occur when the population is concentrated to a certain extent in space, the increase in the scale of labor and 
capital will generate a large number of public service demands, which will encourage cities to increase investment in public service projects, improve infrastructure supporting facilities to enhance social service capabilities, and indirectly enhance the positive externality of ULUE through the effects of public services and supporting facilities [38,39].

Of course, due to the law of diminishing marginal returns, factors do not always play a positive role in the process of flow agglomeration, and they may also mismatch and accumulate some risk factors [40]. Therefore, at different stages of urbanization development, the impact of factor flow on ULUE may also show alternating positive and negative effects. For example, when labor factors are excessively concentrated, problems such as traffic congestion and environmental pollution may occur. The excessive increase of land and capital factors in the middle stage of urbanization may lead to an extensive development mode and the problem of land resource misallocation [41]. In the high-level stage of urbanization, due to the limited supply of land, the scarcity value of land resources is prominent, and the role of land factor flow in promoting ULUE may appear again.

Therefore, according to the above theoretical analysis, the research hypothesis of this paper is summarized as follows.

Hypothesis 1: In the process of urbanization, labor flow, capital flow, and land flow will generally have a significant impact on ULUE.

Hypothesis 2: In different stages of urbanization, labor flow, capital flow, and land flow will have a significantly different impact on ULUE.

\section{Research Methods and Data Sources}

\subsection{Research Method of the Impact of Factor Flow on ULUE}

\subsubsection{Empirical Model}

Based on theoretical analysis, a benchmark regression model of the impact of land, capital, and labor factor flows on ULUE is constructed:

$$
L U E_{i t}=\alpha+\beta_{1} P T_{i t}+\beta_{2} C F T_{i t}+\beta_{3} L F T_{i t}+\beta_{4} \text { Control }_{i t}+\varepsilon_{i t}
$$

In Equation (1), explained variable $L U E_{i t}$ represents the ULUE value of city $i$ in the year $t ; \alpha$ is a constant term; $P F T_{i t}$ represents labor flow, $C F T_{i t}$ represents capital flow, $L F T_{i t}$ represents land flow, and Control $_{i t}$ represents control variable; $\beta_{1}-\beta_{4}$ represents the coefficient to be estimated; $\varepsilon_{i t}$ is the random error term.

\subsubsection{Variable Selection}

Explained variable: ULUE. Stochastic frontier analysis (SFA) is a parameter method for ULUE measurement, which can reflect the statistical characteristics of the sample and the authenticity of the sample calculation. Moreover, it has a good degree of fitting with reality. The measurement efficiency is absolute efficiency, which can be used to analyze the time-series changes of unit efficiency values [42]. Therefore, based on the theoretical model proposed by Battese [43], this paper uses the form of Cobb-Douglas production function to construct an SFA model to measure ULUE. The model is as follows:

$$
\begin{gathered}
\ln Y_{i t}=\alpha_{0}+\alpha_{1} \ln L I_{i t}+\alpha_{2} \ln C I_{i t}+\alpha_{3} \ln P I_{i t}+\left(V_{i t}-U_{i t}\right) \\
L U E_{i t}=\exp \left(-U_{i t}\right)
\end{gathered}
$$

In Equations (2) and (3), $Y_{i t}$ represents the expected output, that is, the non-agricultural economy output value; $\alpha_{0}$ is a constant term; $L I_{i t}$ represents labor inputs, and $C I_{i t}$ represents capital inputs; $P I_{i t}$ represents the undesired output, that is, the pollutant emissions, and the undesired output is included in the model as input variables; it reflects the increase in economic benefits at the expense of ecological environment consumption. Given the availability of data, we have selected three major pollutant indicators: industrial wastewater 
emissions, industrial sulfur dioxide emissions, and industrial soot emissions, and calculated them as comprehensive pollutant indicators as unexpected outputs using entropy; $\alpha_{1}-$ $\alpha_{3}$ is coefficient; $V_{i t}$ is a random error term, which is an uncontrollable factor and has randomness; $U_{i t}$ is an inefficient term, which can be used to calculate technical inefficiency. Refer to the existing research $[3,4,6,8-10]$ and choose the indicators shown in Table 1:

Table 1. Evaluation indicators of the production function.

\begin{tabular}{|c|c|c|}
\hline Index Properties & Indicator Selection & Calculation Method \\
\hline \multirow[b]{2}{*}{ Input } & Labor & $\begin{array}{l}\text { The number of the labor force in the secondary and } \\
\text { tertiary industries/urban construction land area } \\
\text { (person } / \mathrm{km}^{2} \text { ) }\end{array}$ \\
\hline & Capital & $\begin{array}{l}\text { Fiscal expenditure/urban construction land area } \\
\qquad\left(10,000 \mathrm{CNY} / \mathrm{km}^{2}\right) \\
\text { Fixed asset investment/urban construction land area } \\
\left(10,000 \mathrm{CNY} / \mathrm{km}^{2}\right) \\
\text { The actual use of foreign capital in the current year } \\
\text { / urban construction land area }\left(10,000 \mathrm{CNY} / \mathrm{km}^{2}\right)\end{array}$ \\
\hline \multirow[t]{2}{*}{ Output } & Desired output & $\begin{array}{l}\text { Non-agricultural economic output value/urban } \\
\text { construction land area }\left(10,000 \mathrm{CNY} / \mathrm{km}^{2}\right)\end{array}$ \\
\hline & Undesired output & Comprehensive pollution index \\
\hline
\end{tabular}

Core explanatory variables (Table 2) are labor flow, capital flow, land flow. The main form of labor flow is employment transfer, so the labor flow variable is measured by the proportion of employees in the secondary and tertiary industries in the total employment, which is used to reflect the degree of transfer of rural surplus labor to non-agricultural industries in the process of urbanization. Capital flows are generally reflected by the flow of deposits and loans between urban and rural areas. Referring to existing research, the proportion of total deposits and loans of regional financial institutions in GDP is used as the basis for measuring capital flow [44]. The larger the proportion, the more urban development depends on investment, and the greater the intensity of capital flow. The form of land factor flow is land use transformation, which specifically refers to the transformation of rural homesteads, agricultural land, etc., into urban construction land and industrial land by the government through land expropriation. Therefore, the proportion of increased urban construction land area to total urban construction land area is used to measure the flow of land factor.

Table 2. Variable setting.

\begin{tabular}{ccc}
\hline Variable Type & Variable Name & Calculation Method \\
\hline Explained variable & Urban land use efficiency (LUE) & Calculated by the SFA model \\
\hline $\begin{array}{c}\text { Explanatory } \\
\text { variable }\end{array}$ & Labor flow (PFT) & $\begin{array}{c}\text { Secondary and tertiary industry } \\
\text { employment/total employment } \\
\text { Total deposits and loans of regional } \\
\text { financial institutions/GDP } \\
\text { Increased area of urban construction } \\
\text { land / total urban construction } \\
\text { land area }\end{array}$ \\
\hline Control variable & $\begin{array}{c}\text { Land flow (LFT) } \\
\text { thechnological innovation (TL) }\end{array}$ & $\begin{array}{c}\text { Logarithmic value of patents per } \\
10,000 \text { persons }\end{array}$ \\
& The transportation level (CL) & $\begin{array}{c}\text { Logarithmic value of } \\
\text { population density }\end{array}$ \\
& The higher education level (EL) & $\begin{array}{c}\text { Logarithmic value of total road freight } \\
\text { Logarithmic value of the number of } \\
\text { college students }\end{array}$ \\
\hline
\end{tabular}


Control variables: The research shows that the level of scientific and technological innovation, population agglomeration, transportation, and higher education are also important factors affecting ULUE [3-6,9,10,12]. Therefore, the number of patents per 10,000 persons (piece/10,000 persons), population density $\left(10,000\right.$ persons $\left./ \mathrm{km}^{2}\right)$, total road freight (10,000 tons), and the number of college students (persons) can be included as control variables.

\subsubsection{Data Sources and Data Processing}

The basic data used in this paper come from the China Urban Statistical Yearbook, the China Statistical Yearbook 2010-2019, and the statistical yearbooks of provinces and cities. Very few missing data are supplemented by interpolation. At the same time, the research object of this paper is 54 cities in the middle and lower reaches of the Yangtze River (Figure 1). It is one of the regions with the fastest urbanization, the highest degree of marketization, and the strongest economic vitality in China, including 54 cities in seven provincial administrative regions of Hubei, Hunan, Jiangxi, Jiangsu, Zhejiang, Anhui, and Shanghai. It is a significant growth pole supporting China's economic growth, but some problems exist, such as unbalanced urban development and unreasonable factor allocation. The problems of low efficiency of land use are typical all over the country. Research on the region is conducive to understanding the urban land use problems within the region, improving the level of intensive land use, releasing the potential of economic development, and providing reference suggestions for the land use of other cities.

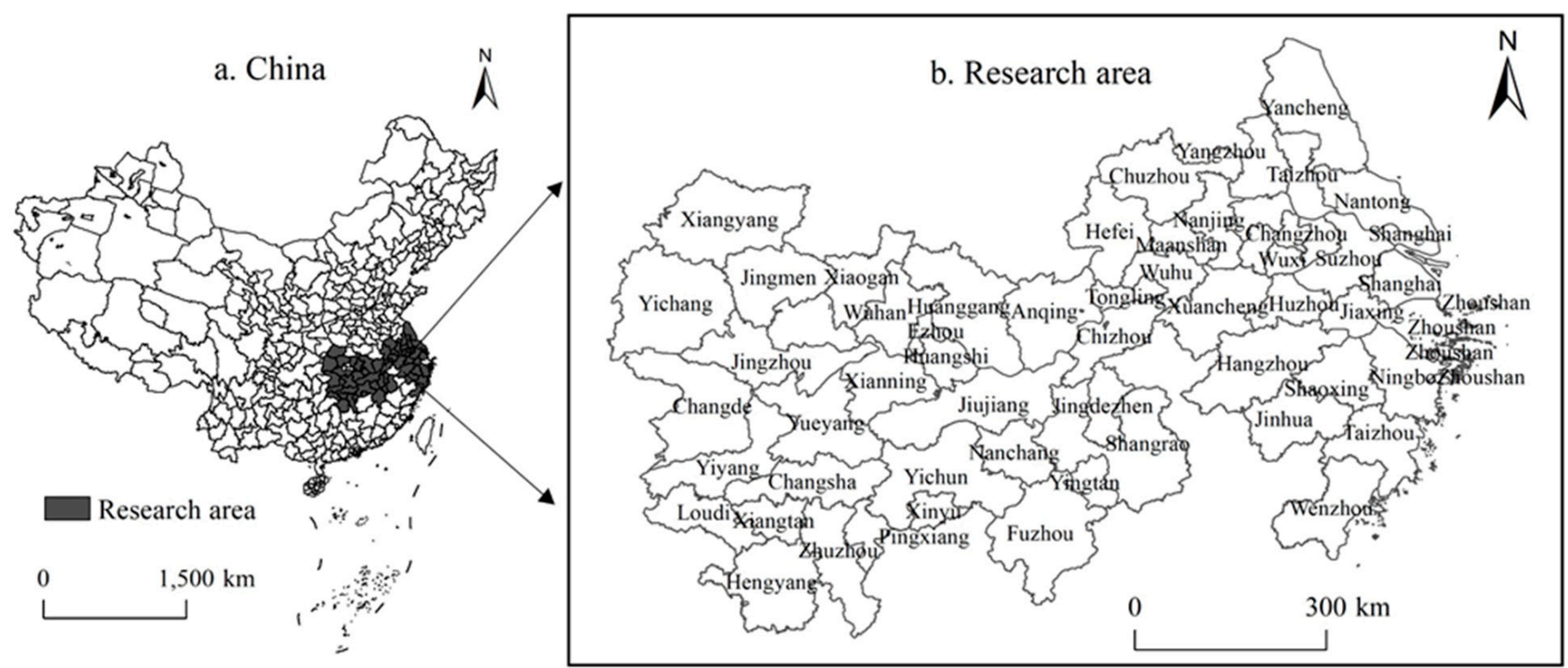

Figure 1. Research area (a) Map of China; (b) 54 cities in the middle and lower reaches of the Yangtze River.

In order to reflect the change of actual level, the research converts GDP, fiscal expenditure, fixed assets investment, total deposits and loans, and the average annual wage income of urban residents into comparable values based on 2009 respectively, and the actual use of foreign capital in that year is converted into CNY units according to the exchange rate of the current year. The data of GDP conversion index and consumer price index are from the National Bureau of Statistics of China, and the exchange rate is from the People's Bank of China. 
3.2. Judgment on the Urbanization Stage of Cities in the Middle and Lower Reaches of the Yangtze River

\subsubsection{Indicator Selection}

Many scholars have discussed in detail the division of urbanization stages in various cities in China. Therefore, this paper draws on the existing research results to build an indicator system for the judgment of urbanization stage [45], including the following four aspects (Table 3): (1) Population urbanization level, the urbanization rate of the resident population is selected as the indicator; (2) Land urbanization level, the urban built area is selected as the indicator; (3) Economic urbanization level, the ratio of the output value of secondary and tertiary industries to GDP is selected as the indicator; (4) Social urbanization level, the average annual wage income of urban residents is selected as the indicator.

Table 3. Indicator system for the judgment of urbanization stage.

\begin{tabular}{ccc}
\hline Index Properties & Indicator Selection & Calculation Method \\
\hline Population urbanization level & $\begin{array}{c}\text { Urbanization rate of resident } \\
\text { population }\end{array}$ & $\begin{array}{c}\text { The urban resident population } \\
\text { is divided by the total } \\
\text { population }\end{array}$ \\
Econd urbanization level & $\begin{array}{c}\text { Urban built area } \\
\text { The ratio of the output value } \\
\text { of secondary and tertiary } \\
\text { industries to GDP } \\
\text { Social urbanization level }\end{array}$ & $\begin{array}{c}\text { Secondary and tertiary } \\
\text { industries divided by total } \\
\text { of urban residents }\end{array}$ \\
\hline
\end{tabular}

\subsubsection{Classification Method}

$\mathrm{K}$-means clustering as proposed by Macqueen is an iterative clustering algorithm that seeks the optimal division in an unsupervised state, which is suitable for sample clustering analysis with a known and an unlabeled number of categories. This method is adopted in this paper for urbanization stage division. The calculation method is as follows.

Assignment: Select K objects as the cluster center, then assign the objects to be classified to the cluster center with the shortest Euclidean distance, and calculate the sum of squares of errors within the group.

The formula for calculating the Euclidean distance between the object to be classified and the cluster center is:

$$
d\left(X, C_{i}\right)=\sqrt{\sum_{j=1}^{m}\left(x_{j}-c_{i j}\right)}
$$

In Equation (4), $X$ is the data object; $C_{i}$ is the $i$ cluster center; $m$ is the classification indicator dimension; $x_{j}$ and $c_{i j}$ are the $j$ indicator attributes of $X$ and $C_{i}$, respectively.

The formula for calculating the sum of the square error is:

$$
S S E=\sum_{i=1}^{k} \sum x \in c_{i}\left|d\left(X, C_{i}\right)\right|^{2}
$$

In Equation (5), $k$ is the number of clusters.

Update: For each newly obtained cluster, take the center of mass of the observed value in the cluster as the new mean point to recalculate the sum of the square error within the group until it does not change.

\subsubsection{Results Analysis}

By using SPSS software, through the K-means clustering method, and combining this with the famous S-shaped curve describing the urbanization trajectory in urban geography, the curve describes that the urbanization process needs to go through the initial stage, acceleration stage, and the later stage. Therefore, this paper divides 54 cities in 2009 into 
three types: the initial stage of urbanization, the expansion stage of urbanization, and the mature stage of urbanization. In order to explore the heterogeneous impact of factor flow on ULUE in different stages of cities, the classification results are shown in Table 4.

Table 4. Results of urbanization stage division.

\begin{tabular}{cccc}
\hline Urbanization Stage & Initial & Expansion & Mature \\
\cline { 1 - 3 } & Yancheng, Xuancheng, & Nantong, Yangzhou, & Shanghai, Nanjing, \\
Chuzhou, Chizhou, & Taizhou, Jiaxing, & Wuxi, Changzhou, \\
& Anqing, Jiujiang, Yingtan, & Huzhou, Shaoxing, & Suzhou, Zhenjiang, \\
Yichun, Shangrao, & Taizhou, Hefei, & Hangzhou, \\
City & Fuzhou, Jingzhou, & Tongling, Maanshan, & Zhoushan, Jinhua, \\
& Xiangyang, Ezhou, & Wuhu, Jingdezhen, & Wenzhou, Ningbo, \\
& Jingmen, Xiaogan, & Pingxiang, Huangshi, & Nanchang, Xinyu, \\
& Huanggang, Xianning, & Yichang, Zhuzhou, & Wuhan, Changsha \\
& Hengyang, Yueyang, & Xiangtan & \\
\hline Changde, Yiyang, Loudi & & & \\
\hline
\end{tabular}

\section{Heterogeneous Results at Different Stages of Urbanization}

\subsection{Regression Analysis}

In this paper, Stata software was used to perform the regression of the mixed OLS model, the random effect model, and the fixed effect model on the overall sample in turn. The regression results are shown in Table 5. In the selection of fixed effect model and random effect model, the Hausman test shows that the fixed effect model is better than the random effect model. Moreover, the data type in this paper is macro data, and a large number of accidental fluctuations are offset by data aggregation, so the fixed effect model is more suitable. The following are the regression results of the fixed effect model.

The regression results of the overall sample show that labor flow and capital flow have a significant promoting effect on ULUE, and the impact coefficients are 0.085 and 0.016 , respectively, both of which are significant at the $1 \%$ level of significance. Land flow has a significant inhibition on ULUE at the 5\% level of significance. It can be seen that factor flow has a certain impact on ULUE, which supports Hypothesis 1 well. The following is a specific analysis of the impact of factor flow on the differentiation of ULUE in cities at different urbanization stages.

\subsection{Heterogeneity Analysis}

(1) In the initial stage of urbanization, labor flow and capital flow are important factors to promote the improvement of ULUE. The impact coefficients of labor flow and capital flow are 0.251 and 0.027 , respectively, which are significant at the $1 \%$ level of significance. The impact coefficient of land flow is -0.016 , which is significant at the $5 \%$ level of significance. The above results show that in the initial stage of urbanization, capital factors and labor factors increase scale efficiency. These two factors can promote the improvement of ULUE, while the extensive urban expansion model makes land have a negative effect on ULUE. 
Table 5. Regression analysis of impact factors of ULUE.

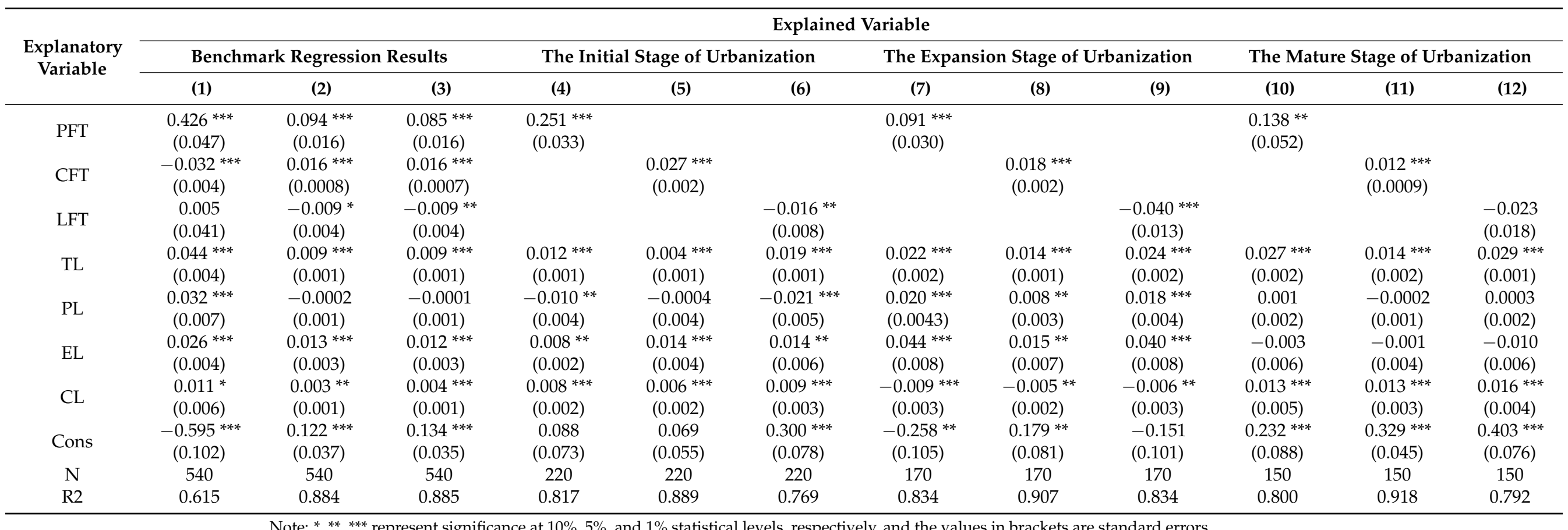

Note: ${ }^{*}{ }^{* *},{ }^{* * *}$ represent significance at $10 \%, 5 \%$, and $1 \%$ statistical levels, respectively, and the values in brackets are standard errors. 
The possible reasons are as follows. On the one hand, the cities at this stage contain a large number of labor-intensive manufacturing industries, and the employment absorbed mainly occurs in the urban sector. The supply of labor depends on the flow of labor from rural to urban areas. The surplus labor supply and low negotiation ability in wage decisions constitute the 'demographic dividend' of economic growth. Labor factors play a significant role in the scale and agglomeration effect [46], which has become an important factor in promoting ULUE. On the other hand, the model of government investmentdriven economic growth in the initial stage of urbanization relies on the support of huge capital liquidity. Capital flow can directly improve regional economic vitality, promote the government to increase infrastructure investment per unit area, and large-scale investment, and construction can meet the rising market demand and drive the improvement of ULUE. In addition, in the process of China's rapid urbanization, the ability of urban governments to scientifically allocate urban land resources and make rational use of urban land lags behind the reality of the rapid expansion of urban construction land. The disorderly expansion of urban land space weakens the ability of the market to allocate production factors, resulting in the decline of land economic output per unit area.

(2) In the expansion stage of urbanization, the impact of labor flow and capital flow on ULUE is significantly positive, and it is significant at the $1 \%$ level of significance, and the impact coefficients are 0.091 and 0.018 , respectively. The impact of land flow still be negative, and the impact coefficient is -0.040 .

Compared with the initial stage, the promotion effect of labor flow has decreased by $63.7 \%$. The promotion effect of capital flow has decreased by $33.3 \%$, which may be due to the fact that factor flow begins to cause diminishing marginal returns for agglomerations. Compared with the initial stage, the urban land use structure in the expansion stage is more rational, and the urban employment channels also show a trend of diversification. However, there is still a problem of low matching between the labor and industrial structures, and there is a certain degree of waste of labor [47]. It means that cities should also pay attention to the coordinated relationship between industrial structure and labor factor endowment when adjusting industrial structure. The city's demand for capital has changed at this stage, and economic growth has changed from high investment-driven to capital quality. If the capital utilization structure is not optimized, and high value-added industries are not developed to absorb capital and increase the return on capital, according to the law of diminishing marginal returns, a large number of capital flows may cause resource waste and efficiency losses, resulting in less and less impact on ULUE.

The inhibition of land flow has increased by $150 \%$. Until urbanization reaches a high level, the negative impact of land flow on ULUE will always exist and gradually increase. Urbanization requires a lot of investment in infrastructure construction, which depends on land finance. The promotion of the championship model of local officials in China stimulates local governments to increase the development of construction land and the expropriation of agricultural land to obtain huge land appreciation income. However, in the short term, large-scale land transfer will lead to the imbalance of land market structure, an imbalance between land supply and demand, and to low ULUE.

(3) In the mature stage of urbanization, the impact of labor flow and capital flow on ULUE is significantly positive, and the impact coefficients are $0.138,0.012$, respectively. The impact of land flow on ULUE is not significant. Capital flow is significantly at the $1 \%$ level of significance, and labor flow is significant at the $5 \%$ level of significance.

With regard to labor flow, in the mature stage of urbanization, perfect infrastructure will continue to attract the inflow of a high-quality labor force, gradually matching the city's industrial structure with the labor endowment. The inflow of a high-quality labor force can not only increase the high value-added income of the industry but also significantly improve the regional consumption level; therefore, the influence coefficient of labor mobility on ULUE increases. With regard to capital flow, the scale of urban infrastructure has been improved, the growth rate of rigid demand and improvement demand for real estate has slowed down, and the investment demand has undergone structural changes. Sustained 
capital investment in the short term will cause waste of resources and loss of efficiency, the decline in returns to scale, and excessive agglomeration of factors, resulting in weakening the role of ULUE. With regard to land flow, as the urban development enters the mature stage, the land factor, as the carrier of high-density urban economic activities, is the fundamental factor of an urban industrial structure optimization, economic transformation, and high-quality development. At this stage, the scarcity of land appears, the flow scale of land gradually weakens, and the negative effect on ULUE will gradually disappear.

(4) From the inspection of the control variables, it can be found that: 1 . The three stages of scientific and technological innovation are significantly positive under the $1 \%$ significance level, indicating that scientific and technological innovation can directly promote urban land use efficiency. 2. The level of population agglomeration has a significant role in promoting urban land use efficiency only in the stage of urbanization expansion and has passed the significance test of $1 \%$. The promotion role is not stable in the other two stages. 3. The level of transportation is significantly positive in the initial and expansion stages of urbanization but not in the mature stages of urbanization. 4. Higher education is significantly positive in the initial and mature stages of urbanization and significantly negative in the expansion stage.

A comprehensive comparison of the regression results of each stage shows that there are apparent differences in the impact of labor flow, capital flow, and land flow on ULUE in different urbanization stages. Firstly, the impact direction of labor flow on ULUE is the same at all stages, and the impact effect is the largest at the initial stage of urbanization, indicating that the 'demographic dividend' brought by labor input at this stage can significantly promote ULUE, which is consistent with the existing research conclusions [48]. However, with the upgrading of industrial structure, the matching degree of productivity and production relations has experienced a process from imbalance to improvement, so the promotion effect presents a 'U' trend. Secondly, the capital flow positively impacts urban land use efficiency in all three stages, but the effect continues to weaken. The possible reason is that in the early stage of urbanization, the government and enterprises have high investment and high exports and have realized the rapid growth of the national economy and the increase of ULUE at the cost of the ecological environment in the short term. However, with the development of urbanization, the investment structure has changed, only focusing on the scale of investment has been difficult to stimulate economic growth continuously. Therefore, only by improving investment efficiency and promoting the optimization of investment structure can we ensure stable economic growth and the steady improvement of ULUE. Finally, the impact of land flow on urban land use efficiency is the negative impact of the initial stage and expansion stage of urbanization, mainly caused by the short-sighted behavior of local governments and unreasonable land use. However, with urbanization, the scarcity of urban land will gradually disappear.

\subsection{Robustness and Endogeneity Tests}

(1) Relaxing the selection conditions of variables and characterizing ULUE by the non-agricultural economic output per unit of urban construction land gives the results shown in Table 5. The symbols of the core explanatory variables are the same as previously. In addition, the significance levels are basically the same, which proves that the previous results have strong robustness.

(2) The endogenous problem is also a problem that needs to be solved in this research. ULUE and factor flow may be mutually causal; that is, factor flow promotes the improvement of ULUE, and the improvement of ULUE may also promote the level of factor flow. Therefore, the data of PFT, CFT, and LFT lagging by one period are taken as explanatory variables, whose logic is that the improvement of ULUE in the current period has almost no impact on the factor flow level of the lagging period. If the factor flow of lagging by one period can still impact ULUE as mentioned above, it indicates that factor flow is the main cause in mutual causation. The results are shown in Table 6. The regression results of the 
lagged data as an explanatory variable are consistent with the previous regression results, which again shows that the previous conclusion is relatively robust.

Table 6. Robustness and endogeneity tests.

\begin{tabular}{|c|c|c|c|c|c|c|}
\hline \multirow{3}{*}{$\begin{array}{c}\begin{array}{c}\text { Explanatory } \\
\text { Variable }\end{array} \\
\text { PFT }\end{array}$} & \multicolumn{6}{|c|}{ Explained Variable } \\
\hline & \multicolumn{3}{|c|}{$\begin{array}{l}\text { Non-Agricultural Economic Output per Unit of } \\
\text { Urban Construction Land }\left(10,000 \mathrm{CNY} / \mathrm{km}^{2}\right)\end{array}$} & \multicolumn{3}{|c|}{$\begin{array}{c}\text { ULUE } \\
\text { (PFT, CFT, and LFT Lagging by One Period) }\end{array}$} \\
\hline & $\begin{array}{c}3.474^{* * *} \\
(0.501)\end{array}$ & $\begin{array}{c}1.231^{* * *} \\
(0.384)\end{array}$ & $\begin{array}{c}2.219^{* * *} \\
(0.827)\end{array}$ & & & \\
\hline CFT & $\begin{array}{c}0.238^{* * *} \\
(0.035)\end{array}$ & $\begin{array}{c}0.109 * * * \\
(0.026)\end{array}$ & $\begin{array}{c}0.139^{* * *} \\
(0.018)\end{array}$ & & & \\
\hline LFT & $\begin{array}{c}-0.295^{* * *} \\
(0.112)\end{array}$ & $\begin{array}{c}-0.377^{* *} \\
(0.173)\end{array}$ & $\begin{array}{l}-0.093 \\
(0.284)\end{array}$ & & & \\
\hline L.PFT & & & & $\begin{array}{c}0.240^{* * *} \\
(0.031)\end{array}$ & $\begin{array}{l}0.181^{* *} \\
(0.080)\end{array}$ & $\begin{array}{l}0.123^{* *} \\
(0.053)\end{array}$ \\
\hline L.CFT & & & & $\begin{array}{c}0.026^{* * *} \\
(0.002)\end{array}$ & $\begin{array}{c}0.017^{* * *} \\
(0.002)\end{array}$ & $\begin{array}{c}0.012 * * * \\
(0.001)\end{array}$ \\
\hline L.LFT & & & & $\begin{array}{c}-0.011 \text { * } \\
(0.006)\end{array}$ & $\begin{array}{c}-0.029 \text { ** } \\
(0.013)\end{array}$ & $\begin{array}{l}-0.020 \\
(0.018)\end{array}$ \\
\hline Control variable & Control & Control & Control & Control & Control & Control \\
\hline $\mathrm{N}$ & 220 & 170 & 150 & 198 & 153 & 135 \\
\hline
\end{tabular}

Note: ${ }^{*},{ }^{* *},{ }^{* * *}$ represent significance at $10 \%, 5 \%$, and $1 \%$ statistical levels, respectively, and the values in brackets are standard errors.

\subsection{Further Discussion}

Based on testing the heterogeneous impact of factor flow on ULUE in cities at different urbanization stages, the threshold effect model is further used to analyze whether there is a threshold value of urbanization level in the process of factor flow affecting ULUE to verify the previous analysis. The model is set according to Hansen's [49] threshold panel model as follows:

$$
y_{i t}=b_{0}+b_{1} x_{i t}\left(\text { thre }_{i t} \leq \gamma\right)+b_{2} x_{i t}\left(\text { thre }_{i t}>\gamma\right)+b_{n} X+\varepsilon_{i t}
$$

In Equation (6), $y_{i t}$ is ULUE; $x_{i t}$ is the factor flow variable; thre $e_{i t}$ is the threshold variable of urbanization rate, $\gamma$ is the threshold value; $X$ are the control variables, which are the level of technological innovation, population agglomeration, transportation, and higher education; $\varepsilon_{i t}$ is the random error term.

In Table 7, the results show a single threshold for labor flow, which is 32.00 . The differential impact of labor flow on ULUE is mainly reflected in the period of low urbanization. There is a double threshold for capital flow, which is 50.42 and 73.25 respectively, with an obvious gradient. There is a single threshold for land flow, which is 40.71 . The results generally prove that there is a threshold value of urbanization level in the process of factor flow affecting ULUE, but the threshold values of different factors are different. In connection with the above, the influence coefficient of labor flow in the initial stage of urbanization is the most obvious. The promotion effect of capital flow decreases gradually with the increase of the urbanization rate. Land flow plays an inhibitory role in the initial stage of urbanization and the expansion stage of urbanization. The threshold model also verifies the above analysis well. 
Table 7. Threshold effect test results.

\begin{tabular}{cccccccc}
\hline $\begin{array}{c}\text { Variable } \\
\text { Name }\end{array}$ & Model & F Value & p Value & $\begin{array}{c}\text { Threshold } \\
\text { Value }\end{array}$ & $\begin{array}{c}\mathbf{1 \%} \text { Critical } \\
\text { Value }\end{array}$ & $\begin{array}{c}\mathbf{5 \%} \text { Critical } \\
\text { Value }\end{array}$ & $\begin{array}{c}\mathbf{1 0} \% \text { Critical } \\
\text { Value }\end{array}$ \\
\hline PFT & Single threshold & $42.47^{* *}$ & 0.043 & 32.00 & 54.100 & 40.822 & 34.073 \\
\hline \multirow{2}{*}{ CFT } & Single threshold & $31.72^{* *}$ & 0.043 & 73.25 & 41.980 & 29.997 & 25.657 \\
& Double threshold & $31.74^{* *}$ & 0.033 & 50.42 & 43.878 & 26.494 & 23.767 \\
\hline LFT & Single threshold & $23.79 * *$ & 0.040 & 40.71 & 29.771 & 21.935 \\
\hline
\end{tabular}

Note: ${ }^{*}, * * * * *$ represent significance at $10 \%, 5 \%$ and $1 \%$ statistical levels, respectively. The number of threshold tests of BS was obtained 300 times by automatic sampling.

\section{Discussion}

\subsection{Theoretical and Practical Value}

In this research, we found that factor flow significantly impacts ULUE and is heterogeneous in different urbanization stages. First, labor flow plays a significant role in improving ULUE, which is generally consistent with the existing research conclusions. However, the existing research ignores the ' $U$ ' trend with the impact of labor flow in the urbanization process, which reflects the process of the adaptation of labor factors to the industrial structure. This ' $U$ ' relationship is of great practical significance for adjusting the scale and structure of labor mobility and guiding urban industrial upgrading and economic transformation. Secondly, the role of capital flow in promoting ULUE has also been confirmed, but most research ignores the reality that this role continues to weaken under urbanization. It reminds urban managers that with the development of urbanization, the high investment model that only focuses on the scale of capital flows urgently needs to be changed. Finally, the land flow has a significant inhibitory effect on ULUE in the initial and expansion stages of urbanization. Urbanization will inevitably be accompanied by the non-agriculturalization of a large amount of land. The land flowing from rural areas to cities seems to be inexhaustible for urban managers. The inflow of land is extensive and inefficiently used. The rapid expansion of urban space that does not match economic progress in a short time reduces the economic output per unit of land. These are all relevant theoretical values obtained from this research.

This research is also of great reference significance for the development of other developing countries and regions. China is the largest developing country in the world. At the same time, the imbalance in regional development has led to a significant difference in the urbanization process among cities. This reality has also been well reflected in the research area. The middle and lower reaches of the Yangtze River urban agglomerations include well-known international metropolises such as Shanghai, regional center cities such as Nanjing and Wuhan, and low-urbanized cities such as Anqing and Yichun. There are still many developing countries with insufficient and uneven urbanization in the world. Although these developing countries have different political systems, cultural concepts, and economic bases, they all share the phenomenon of factor flow from rural to urban areas and varying degrees of land use problems. The different urbanization stages have corresponding cities and regions in China and can help formulate reasonable and effective policies and measures based on China's experience.

\subsection{Policy Enlightenment}

This research puts forward the following policy suggestions with universal applicability:

(1) The role of the market has been unanimously affirmed by Marx's political economy and Western economics [50]. We should give full play to the decisive role of the market in the allocation of factors, especially the institutional shackles and obstacles that restrict the role of the market in developing countries. We should deepen market-oriented reform and institutional renewal, promote the free and smooth flow of labor, capital, land, and other factors of production, strengthen the contribution of factors to the high-quality development of cities, and thus improve ULUE. 
(2) According to the urbanization stage of the city, the government should combine theory with practice to implement differentiated policies. Given the critical role of labor flow and capital flow in promoting ULUE in the initial stage of urbanization and the expansion stage of urbanization, we should continue to improve the labor security system, standardize the operation mechanism of the labor market, and pay attention to the scale and quality of capital flow. However, we should be vigilant against the inefficiency of urban land use caused by the imbalance between labor mobility and industrial structure. In view of the inhibitory effect of land flow on ULUE, the government is required to reasonably measure the scarcity of land factors according to the regional natural resource endowment. In the early stage of urbanization, it is necessary to establish a sense of intensive and economical use of land and put an end to the severe consequences caused by the urban sprawl without any control.For cities in the mature stage of urbanization, we should continue to pay attention to the impact of land flow on ULUE, reasonably control the amount of land flow, scientifically allocate the use of land, maximize the macro-control role of the government on land, and be alert to the inverted U-shaped impact of the scale level of capital factors on urban economic development.

\section{Conclusions}

This paper uses panel data from 54 cities in the middle and lower reaches of the Yangtze River in China from 2009 to 2018 to empirically analyze the heterogeneity of the flow of three major factors of production of labor, capital, and land on ULUE at different urbanization stages and analyzes the threshold effect of urbanization level on ULUE. The main research conclusions are as follows: (1) Labor flow and capital flow all play a significant role in promoting ULUE; land flow plays the opposite role. (2) With the continuous improvement of the level of urbanization, the promotion effect of labor flow first decreases and then increases, while the promotion effect of capital flow continues to decrease, and the inhibitory effect of land flow is significant in the initial stage and expansion stage of urbanization, and the effect increases gradually, but it is not significant in the mature stage. (3) The level of urbanization has a noticeable threshold effect on factor flow. There are single thresholds for labor flow and land flow, and there is a double threshold for capital flow.

It should be noted that there are some shortcomings in this research: (1) According to the Opinions on Building a Perfect System and Mechanism for Market-oriented Allocation of Factors issued by the Chinese government, the document defines five elements for China's economy, namely: labor, capital, land, technology, and data. However, the research on technology flow and data flow is not sufficient. This research can only discuss the urban land use problem in China based on the traditional flow of three major factors of production: land, labor, and capital. (2) Land factors are relatively scarce for cities with high urbanization rates. The inflow of land factors can alleviate land scarcity and meet the material needs of high-quality urban development, thus improving ULUE. However, this research does not effectively confirm the above analysis. (3) The mechanism and path of factor flow affecting ULUE are complex. This research only considers the direct impact of factor flow on ULUE.

Based on the shortcomings of this research, the following directions of research significance are proposed for reference: (1) Against the background of the rapid development of digital technology, it is of great significance to study the impact of technology flow and data flow on ULUE in today's development of urbanization into a new stage of digitization and intelligence. (2) The problem of reverse urbanization has gradually emerged, and the flow of urban and rural factors has gradually changed from a one-way flow to a two-way flow of urban and rural factors, but the research on two-way flow is missing. (3) Considering the indirect impact of factor flow on ULUE, which variables play an intermediary role? What is the effect of indirect effects? Is there stage heterogeneity and regional heterogeneity? To sum up, these problems need to be solved urgently. 
Author Contributions: Conceptualization, X.L., J.L. and Z.S.; methodology, J.D.; software, J.H.; validation, J.L., Z.S. and X.L.; formal analysis, J.D.; investigation, J.H.; resources, J.L.; data curation, Z.S.; writing-original draft preparation, J.L. and Z.S.; writing-review and editing, Z.S. and M.S.; visualization, J.L.; supervision, X.L.; project administration, X.L.; funding acquisition, X.L. All authors have read and agreed to the published version of the manuscript.

Funding: This research was funded by the National Natural Science Foundation of China (Grant No. 41901256, 71673096, 42001229), Humanity and Social Science Research Funds of Ministry of Education (MOE) of China (Grant No. 21YJC790006).

Data Availability Statement: The data presented in this study are available on request from the first author.

Acknowledgments: The authors would like to thank Bing Kuang, Danling Chen, Fenghang Li, and Siqian Zhou for their thoughts and suggestions.

Conflicts of Interest: The authors declare no conflict of interest.

\section{References}

1. Gao, J.; O'Neill, B.C. Mapping global urban land for the 21st century with data-driven simulations and Shared Socioeconomic Pathways. Nat. Commun. 2020, 11, 2302. [CrossRef] [PubMed]

2. Krekel, C.; Kolbe, J.; Wuestemann, H. The greener, the happier? The effect of urban land use on residential well-being. Ecol. Econ. 2016, 121, 117-127. [CrossRef]

3. Yu, J.; Zhou, K.; Yang, S. Land use efficiency and influencing factors of urban agglomerations in China. Land Use Policy 2019, 88, 104143. [CrossRef]

4. Gao, X.; Zhang, A.; Sun, Z. How regional economic integration influence on urban land use efficiency? A case study of Wuhan metropolitan area, China. Land Use Policy 2020, 90, 104329. [CrossRef]

5. Yang, Q.K.; Duan, X.J.; Wang, L.; Wang, K.; Fan, Y.T.; Zhu, G.L. Collaborative measurement and interactive response between regional integration and urban land use efficiency in the Yangtze River Delta. Resour. Sci. 2021, 43, 2093-2104. [CrossRef]

6. Zhang, W.X.; Zou, J.L.; Wu, Q. Effect of production factors on urban land use efficiency: Based on the provincial data of different development stages. Resour. Sci. 2020, 42, 1416-1427. [CrossRef]

7. Stiglitz, J.E.; Yusuf, S. Rethinking the East Asian Miracle; Oxford University Press: Oxford, UK, 2001.

8. Chen, Y.; Chen, Z.; Xu, G.; Tian, Z. Built-up land efficiency in urban China: Insights from the general land use plan (2006-2020). Habitat Int. 2016, 51, 31-38. [CrossRef]

9. Tang, Y.K.; Wang, K.; Ji, X.M.; Xu, H.; Xiao, Y.Q. Assessment and Spatial-Temporal Evolution Analysis of Urban Land Use Efficiency under Green Development Orientation: Case of the Yangtze River Delta Urban Agglomerations. Land 2021, 10, 715. [CrossRef]

10. Liu, S.; Xiao, W.; Li, L.; Ye, Y.; Song, X. Urban land use efficiency and improvement potential in China: A stochastic frontier analysis. Land Use Policy 2020, 99, 105046. [CrossRef]

11. Deng, X.; Gibson, J. Sustainable land use management for improving land eco-efficiency: A case study of Hebei, China. Ann. Oper. Res. 2020, 290, 265-277. [CrossRef]

12. Liu, S.; Lin, Y.; Ye, Y.; Xiao, W. Spatial-temporal characteristics of industrial land use efficiency in provincial China based on a stochastic frontier production function approach. J. Clean. Prod. 2021, 295, 126432. [CrossRef]

13. Qiao, W.; Huang, X. Change in Urban Land Use Efficiency in China: Does the High-Speed Rail Make a Difference? Int. J. Environ. Res. Public Health. 2021, 18, 10043. [CrossRef] [PubMed]

14. Zhao, Z.; Bai, Y.; Wang, G.; Chen, J.; Yu, J.; Liu, W. Land eco-efficiency for newtype urbanization in the Beijing-Tianjin-Hebei Region. Technol. Forecast. Soc. Change 2018, 137, 19-26. [CrossRef]

15. Liu, Y.; Wang, L.; Long, H. Spatio-temporal analysis of land-use conversion in the eastern coastal China during 1996-2005. J. Geogr. Sci. 2008, 18, 274-282. [CrossRef]

16. He, S.; Yu, S.; Li, G.; Zhang, J. Exploring the influence of urban form on land-use efficiency from a spatiotemporal heterogeneity perspective: Evidence from 336 Chinese cities. Land Use Policy 2020, 95, 104576. [CrossRef]

17. Xie, H.; Chen, Q.; Lu, F.; Wang, W.; Yao, G.; Yu, J. Spatial-temporal disparities and influencing factors of total-factor green use efficiency of industrial land in China. J. Clean. Prod. 2019, 207, 1047-1058. [CrossRef]

18. Pu, W.; Zhang, A.; Wen, L. Can China's Resource-Saving and Environmentally Friendly Society Really Improve the Efficiency of Industrial Land Use? Land 2021, 10, 751. [CrossRef]

19. Peng, C.; Xiao, H.; Liu, Y.; Zhang, J. Economic structure and environmental quality and their impact on changing land use efficiency in China. Front. Earth Sci. 2017, 11, 372-384. [CrossRef]

20. Jiang, X.; Lu, X.H.; Liu, Q.; Chang, C.; Qu, L.L. The effects of land transfer marketization on the urban land use efficiency: An empirical study based on 285 cities in China. Ecol. Indic. 2021, 132, 108296. [CrossRef]

21. Liu, Y.; Fan, P.; Yue, W.; Song, Y. Impacts of land finance on urban sprawl in China: The case of Chongqing. Land Use Policy 2018, 72, 420-432. [CrossRef] 
22. Chen, L.; Hu, L.J.; He, F. Factor flow, market integration and economic development-An empirical study based on Chinese provincial panel data. Inq. Econ. Issues 2019, 56-69.

23. Restuccia, D.; Rogerson, R. Misallocation and productivity. Rev. Econ. Dyn. 2013, 16, 1-10. [CrossRef]

24. Lynch, K. Rural-Urban Interaction in the Developing World; Routledge: London, UK; New York, NY, USA, 2005 ; pp. 13-16.

25. Huang, L.; Wu, C.Q. Industrial green development efficiency and spatial driven mechanism in cities of the Yangtze River Economic Belt. China Popul. Resour. Environ. 2019, 29, 40-49.

26. Wong, L.; Wai-Po, H. Reforming the household registration system: A preliminary glimpse of the blue chop household registration system in Shanghai and Shenzhen. Int. Migr. Rev. 1998, 32, 974-994. [CrossRef]

27. Yan, S.Q.; Ge, X.J.; Wu, Q. Government intervention in land market and its impacts on land supply and new housing supply: Evidence from major Chinese markets. Habitat Int. 2014, 44, 517-527. [CrossRef]

28. Qu, S.J.; Hu, S.G.; Li, Q.F. Stages and spatial patterns of urban built-up land transition in China. Acta Geogr. Sin. 2022, 75, 1539-1553.

29. Yu, Y.X.; Zhang, P. Discussion on the Inflection Point of Lewis in China under the Framework of the Lewis Model: An Empirical Study from Microdata of Enterprises. World Econ. Pap. 2011, 1, 32-45.

30. Kuang, Y.P. China's Income Gap between Urban and Rural: An Explanation from of the Flow Factors Income. Issues Agric. Econ. 2013, 34, 76-84.

31. Henderson, J.V. Marshall's scale economies. J. Urban Econ. 2003, 53, 1-28. [CrossRef]

32. Liu, P.; Ravenscroft, N. Collective action in implementing top down land policy: The case of Chengdu, China. Land Use Policy 2017, 65, 45-52. [CrossRef]

33. Han, F.; Xie, R.; Fang, J.; Liu, Y. The effects of urban agglomeration economies on carbon emissions: Evidence from Chinese cities. J. Clean. Prod. 2018, 172, 1096-1110. [CrossRef]

34. Fujita, M.; Krugman, P.; Venables, A. The Spatial Economy: Cities, Regions, and International Trade; MIT Press: Cambridge, MA, USA, 1999.

35. Ge, K.; Zou, S.; Chen, D.L.; Lu, X.H.; Ke, S.G. Research on the Spatial Differences and Convergence Mechanism of Urban Land Use Efficiency under the Background of Regional Integration: A Case Study of the Yangtze River Economic Zone, China. Land 2021, 10, 1100. [CrossRef]

36. Tumwebaze, H.K.; Ijjo, A.T. Regional economic integration and economic growth in the COMESA Region, 1980-2010. Afr. Dev. Rev. 2015, 27, 67-77. [CrossRef]

37. Wu, C.; Wei, Y.D.; Huang, X.; Chen, B. Economic transition, spatial development and urban land use efficiency in the Yangtze River Delta, China. Habitat Int. 2017, 63, 67-78. [CrossRef]

38. Zhao, D.D.; Hu, Y.C. Quantitative study of the interaction between intensive land use and urbanization in three urban agglomerations of China. Geogr. Res. 2016, 35, 2105-2115.

39. Lu, X.H.; Chen, D.L.; Kuang, B. Indicator system design and regional difference of urban land use efficiency under the background of regional integration: A case of urban agglomeration in the middle reaches of the Yangtze River. China Popul. Resour. Environ. 2018, 28, 102-110.

40. Aoki, S. A simple accounting framework for the effect of resource misallocation on aggregate productivity. J. Jpn. Int. Econ. 2012, 26, 473-494. [CrossRef]

41. Ma, A.H.; He, Y.Y.; Tang, P. Understanding the Impact of Land Resource Misallocation on Carbon Emissions in China. Land 2021, 10, 1188. [CrossRef]

42. Liu, S.C.; Ye, Y.M.; Xiao, W. Spatial-Temporal Differentiation of Urban Land-Use Efficiency in China Based on Stochastic Frontier Analysis. China Land Sci. 2020, 34, 61-69.

43. Battese, G.; Coelli, T. A model for technical inefficiency effects in a stochastic frontier production function for panel data. Empir Econ. 1995, 20, 325-332. [CrossRef]

44. Du, S.Z.; Xian, G.M.; Leng, Y.L. China's Financial Development, Capital Efficiency and OFDI. J. Quant. Tech. Econ. 2016, 33, 17-36.

45. Chen, M.X.; Lu, D.D.; Zhang, H. Comprehensive Evaluation and the Driving Factors of China's Urbanization. Acta Geogr. Sin. 2009, 64, 387-398.

46. Tombs, T.; Zhu, X. Trade, migration, and productivity: A quantitative analysis of China. Am. Econ. Rev. 2019, 109, 1843-1872. [CrossRef]

47. Xiao, Y.; Ma, D.D.; Cheng, Y.T.; Wang, L. Effect of Labor Cost and Industrial Structure on the Development Mode Transformation of China's Industrial Economy. Emerg. Mark. Financ. Trade 2019, 56, 1677-1690. [CrossRef]

48. Gu, N.H.; Chen, X.Y. Fiscal constraints, urban expansion and economic agglomeration density, labor productivity changes. Economist 2015, 6, 30-40.

49. Bruce, E.H. Threshold effects in non-dynamic panels: Estimation, testing, and inference. J. Econom. 1999, 93, 345-368.

50. Hong, Y.X. Theoretical study of allowing the market to play a decisive role in allocating resources and improving the government's role. Econ. Theory Bus. Manag. 2014, 10, 5-13. 